\title{
CAUDAL EPIDURAL FOR POSTOPERATIVE ANALGESIA IN MALE CHILDREN
}

\author{
Jan Muhammad Shaikh, Sikandar Ali Mughal, Sher Muhammad Shaikh, \\ Faisal Ghani Siddiqui and Amna Memon
}

\begin{abstract}
OBJECTIVE: To assess the duration and safety of single dose caudal epidural with bupivacaine for postoperative analgesia in children.

DESIGN: A descriptive study.

SETTING: Chandka Medical College Hospital, Larkana from February 2002 to September 2004.

PATIENTS AND METHODS: One hundred and seventy six boys, ASA-I, between the ages of 2 to 8 years, scheduled for inguinal or penile surgery, were randomly assigned in a prospective fashion to receive single shot caudal epidural with bupivacaine $0.25 \%, 0.75 \mathrm{ml} . \mathrm{kg}-1$, and studied for postoperative pain relief. Pain was evaluated by using faces pain scale. Analgesia was administered when pain scale was 3-4. Postoperative complications were also noted. RESULTS: Mean duration of analgesia was $10.43 \pm 3.4$ hours. Time for micturation was $161.79 \pm$ 83.2 minutes while time to stand was $161.21 \pm 69.65$ minutes. Haemodynamic and respiratory parameters remained stable during the observation period. Frequency of postoperative nausea and vomiting was $7 \%$ while urinary retention occurred in $1.4 \%$ patients.

CONCLUSION: Caudal epidural analgesia with bupivacaine $0.25 \%$ in a dose of $0.75 \mathrm{ml} . \mathrm{kg}-1$ provides safe and effective postoperative pain relief in children undergoing inguinal and penile surgery, with very few complications.
\end{abstract}

KEY WORDS: Caudal Epidural. Bupivacaine. Postoperative analgesia. Children.

\section{INTRODUCTION}

Single shot caudal epidural analgesia is a widely used regional technique for intra and postoperative pain relief during lower abdominal, inguinal and penoscrotal surgeries in paediatric patients. ${ }^{1-4}$ It is technically simple, safe and reliable, and provides effective analgesia for surgery below umbilicus. ${ }^{5}$ Caudal epidural offers several advantages when combined with general anaesthesia including lower volatile anaesthetic requirement, rapid and comfortable recovery, excellent analgesia and decreased blood loss. ${ }^{6}$ A single shot caudal epidural, when administered before the start of surgery, has anaesthetic-sparing properties and provides analgesia before child's emergence from anaesthesia. ${ }^{7}$ With bupivacaine, caudal epidural can provide analgesia for 4 to 24 hours postoperatively. ${ }^{8-11}$ Bupivacaine is a long acting amide local anaesthetic agent. It is routinely used for caudal epidural analgesia in children because of its long duration of action and beneficial ratio of sensory to motor block. Maximum safe dose of bupivacaine as a single injection is $2.5 \mathrm{mg} . \mathrm{kg}-1$ and the preferred concentration for caudal epidural is $0.25 \%{ }^{12}$ Approximately, 0.75 to $1 \mathrm{ml} . \mathrm{kg}-1$ of local anaesthetic agent is required for analgesia up to T-10 level. ${ }^{13}$ However, bupivacaine is associated with a number of side effects, including urinary reten- tion. ${ }^{12}$ We conducted this study to assess the duration and safety of single shot caudal epidural analgesia with bupivacaine $0.25 \%$, in a dose of $0.75 \mathrm{ml} . \mathrm{kg}-1$.

\section{PATIENTS AND METHODS}

This study was conducted at Chandka Medical College Hospital, Larkana - Sindh from February 2002 to September 2004. Patients were eligible if they were male children, aged 2-8 years, ASA status I and scheduled for elective surgery. Patients were excluded if they had local infection, preexisting neurological disease, bleeding diathesis or aspirin or any other analgesic ingestion in the preceding week. Patients in which caudal block failed were also excluded from the study. Written informed consent was obtained from parents or guardians of all patients. No premedication was given. Anaesthesia was induced with injection thiopentone sodium 3-5mg.kg-1 or halothane and oxygen by facemask, and endotracheal intubation was done using injection suxamethonium 1.5-2 mg.kg-1. Nitrous oxide was not used because of its nonavailability at this set up at that time. Anaesthesia was maintained with $1-2 \%$ halothane in $100 \%$ oxygen on spontaneous ventilation. Caudal block was performed using a standard aseptic technique by a consultant anaesthetist. The child was placed in the left lateral position and the sacral hiatus punctured using a 23-G 
intravenous needle. After careful aspiration, when there was no evidence of intrathecal or intravascular malposition of the needle, bupivacaine plain $0.25 \%$, 0.75 ml.kg-1 was given. The child was then turned supine and underwent standard surgical procedure. Surgery started atleast 15 minutes after caudal injection. During anaesthesia, heart rate and $\mathrm{SpO} 2$ were monitored continuously and arterial blood pressure was measured every 5 minutes by noninvasive means. Postoperatively, patients were accompanied to the recovery area and subsequently to the ward by another anaesthetist. Before transfer from recovery area to the ward, all patients were fully awake. Postoperative pain was assessed using Faces Pain Scale. A faces rating scale for pain from 1 (no pain) to 6 (worst pain) was used. The pain was classified as no or mild pain (faces scale 1-2), moderate (3-4) and severe pain (5-6). These scores were assessed at 30 minutes intervals for first 2 hours and then hourly until patient received rescue analgesia. Additional assessments were performed if child complained of pain. Analgesia was administered when faces pain scale score was 3-4. Further assessments regarding pain were stopped if patient received additional analgesia in the form of parenteral opioids or oral analgesics. Children who were asleep were designated as free of pain and were left undisturbed. In addition, time to first micturation and ability to stand were also recorded. Duration of analgesia was defined as the time from caudal injection to the first analgesic requirement. Side effects, if any, specially urinary retention and postoperative nausea and vomiting were also recorded. All results were expressed as Mean \pm Standard Deviation. SPSS 10.0 was used for statistical calculations.

\section{RESULTS}

Total one hundred and seventy-six ASA-I boys, aged 2-8 years were included in the study. All patients were found to have successful intra-operative analgesia by the anaesthetist conducting general anaesthesia, and none of the patients required additional analgesia during surgery. Demographic data, duration of surgery and duration of anaesthesia are presented in Table $\mathbf{I}$. The surgical procedures were classified into four groups, as shown in Table II. Duration of analgesia, time to micturation and time to stand are presented in Table III. Bupivacaine at a concentration of $0.25 \%$ in a dose of $0.75 \mathrm{ml} . \mathrm{kg}-1$ produced reliable postoperative analgesia in all children with very few complications. Additional analgesics during surgery were not required in any child. Postoperative nausea and vomiting was reported in 12 patients, giving an emetic incidence of $7 \%$. Patients undergoing hypospedias repair were catheterized at the end of surgery due to surgical demands. Of the remaining patients, urinary retention developed in 2 (1.4\%) boys, requiring catheterization for 12 hours. No haemodynamic or respiratory side effects or adverse events were observed intra or postoperatively.

TABLE I:

DEMOGRAPHIC PATTERN AND DURATIONS OF SURGERY AND ANAESTHESIA

\begin{tabular}{|l|c|}
\hline Age (years) & $4.60 \pm 1.88$ \\
\hline Weight $\left(\mathrm{kg}^{\star}\right)$ & $16.16 \pm 3.5$ \\
\hline Duration of Anaesthesia (min**) & $63.15 \pm 15.15$ \\
\hline Duration of Surgery $(\mathrm{min})$ & $34.9 \pm 14.55$ \\
\hline
\end{tabular}

* Kilogram ** Minutes

TABLE II:

SURGICAL PROCEDURES PERFORMED AMONG CASES $(n=176)$

\begin{tabular}{|l|c|}
\hline \multicolumn{1}{|c|}{ Procedure } & Number of Patients \\
\hline Inguinal Hernia & 82 \\
\hline Hydrocele & 37 \\
\hline Orchidopexy & 24 \\
\hline Hypospedias & 33 \\
\hline
\end{tabular}

TABLE III:

DURATIONS OF ANALGESIA, MICTURATION AND STANDING

\begin{tabular}{|l|c|}
\hline \multicolumn{1}{|c|}{ Duration } & Number of Patients \\
\hline Duration of analgesia (hours) & $10.43 \pm 3.4$ \\
\hline Time to micturation (min) & $161.79 \pm 83.2$ \\
\hline Time to stand (min) & $161.21 \pm 69.65$ \\
\hline
\end{tabular}

\section{DISCUSSION}

Caudal epidural block is a widely used regional technique for intra and post-operative pain relief during lower abdominal, inguinal and penoscrotal surgeries in paediatric patients. ${ }^{2,14}$ The caudal approach is easy and provides excellent analgesia for surgery below umbilicus. In paediatric patients, caudal epidural block is widely used as an adjunct to general anaesthesia and for post-operative pain relief.

It is better to administer epidural before the start of surgery to have the advantage of anaesthetic-sparing properties and provide analgesia before child emerges from anaesthesia. ${ }^{15}$ Although, caudal epidural with local anaesthetics delays voiding, children do void on an average of 6-8 hours when using bupiva- 
caine concentration of $0.25 \%$ or less. ${ }^{15}$ True urinary retention occurs rarely. ${ }^{16}$ In this study, we found that duration of analgesia with caudal epidural bupivacaine was $10.43 \pm 3.4$ hours. The duration of analgesia by single shot caudal epidural with bupivacaine $0.25 \%$, as reported in different studies, is variable and differs largely ranging from 2-6 hours ${ }^{17}$ to 24 hours. ${ }^{10}$ Findings of this study are in agreement with a study by Fauzia and colleagues, and Mahajan, et $\mathrm{al}^{18,19}$, in which duration of analgesia was $9.97 \pm 2.25$ hours and 7-10 hours respectively. In the study by Jamali and colleagues $^{20}$, duration of analgesia was $7.66 \pm 7.31$ hours. Interestingly, duration of analgesia reported in some studies was much prolonged as compared to this study. Salahuddin, et $\mathrm{al}^{21}$ have reported effective analgesia for 12-18 hours, while a study by Riaz and colleagues $^{22}$ reports analgesia for $12-24$ hours. Probably, social circumstances as well as premedication and methods of pain assessment influenced the results. We used faces pain scale for measurement of post-operative pain, which is reported to be a reliable and valid method. ${ }^{23,24}$ Total incidence of postoperative nausea and vomiting in this study was $7 \%$. In some studies, no patient suffered post-operative vomiting $^{17,23,13}$, while in one study ${ }^{24}$, it was $3.3 \%$. Perhaps, smaller sample size in these studies resulted in this lower frequency of post-operative nausea and vomiting. In this study, urinary retention occurred in 2 patients out of 143 , giving an over all incidence of $1.4 \%$, while Fauzia, et $\mathrm{al}^{18}$ have reported $6.6 \%$ incidence.

\section{CONCLUSION}

We conclude that single shot caudal epidural block with bupivacaine $0.25 \%$ in a dose of $0.75 \mathrm{ml} . \mathrm{kg}-1$ for post-operative pain relief in children is a simple, safe and effective technique. Its practice is recommended for post-operative pain management in children undergoing inguinal and penile surgery.

\section{REFERENCES}

1. Giaufre E, Dalens B, Gombert A. Epidemiology and morbidity of regional anesthesia in children: $A$ one year prospective survey of French-Language Society of Pediatric Anesthesiologists. Anesth Analg. 1996; 83:94-112.

2. Klimscha W, Chiari A, Michalek-Sauberer A, Wildling $E$, Lerche $A$, Lorber $C$, et al. The efficacy and safety of a clonidine/bupivacaine combination in caudal blockade for paediatric hernia repair.
Anesth Analg. 1998; 86:54-61.

3. Lloyd-Thomas AR. Pain management in paediatric patients. Br J Anaesth. 1990; 64:85-104.

4. Lee JJ, Rubin AP. Comparison of a bupivacaineclonidine mixture with plain bupivacaine for caudal analgesia in children. Br J Anaesth. 1994; 72:25862.

5. Meakin G, Anaesthesia for infants and children. In: Thomas EJH, Peter JC. Wylie and Churchill Davidson's A Practice of Anesthesia. $6^{\text {th }}$ Edition. Edward Arnold. 1995:p.684.

6. Gunter JB, Forestner JE, Manley CB. Caudal epidural anaesthesia reduces blood loss during hypospedias repair. J Urol.1990;144:517- 9.

7. Joelle FD, Terrance AY. Problems with pediatric postoperative pain control. In: Terrance AY. Paediatric Anaesthesia Handbook. USA, McGraw-Hill, 2002: p.380.

8. Sharpe P, Klein JR, Thompson JP, Rushman SC, Sherwin J, Wandless JG, et al. Analgesia for circumcision in a paediatric population: comparison of caudal bupivacaine alone with bupivacaine plus two doses of clonidine. Paediatric Anaesthesia 2001; 11:695-700.

9. Wilson PT, Lloyd Thomas AR. An audit of extradural infusion analgesia in children using bupivacaine and diamorphine. Anaesthesia. 1993; 48:718.

10. Gunduz M, Ozcengiz D, Ozbek H, Isik G. A comparison of single dose caudal tramadol, tramadol plus bupivacaine and bupivacaine administration for postoperative analgesia in children. Paediatric Anaesthesia. 2001; 11:323-26.

11. Samuel $M$, Hampson-Evans $D$, Cunnington $P$. Prospective to a randomized double-blind controlled trial to assess efficacy of double caudal analgesia in hypospadias repair. J Pediatr Surg. 2002;37(2):168-74.

12. de Beer DAH, Thomas ML. Caudal additives in children-solutions or problems? $\mathrm{Br} \mathrm{J}$ Anaesth. 2003; 90: 487-98.

13. Manjushree R, Basu SM. Postoperative analgesia in paediatric day care surgery. Ind J Anaesth. 2000;12:1-2.

14. Dalens B, Hasnaoui A. Caudal anaesthesia in pediatric surgery: Success rate and adverse effects in 750 consecutive patients. Anesth Analg. 1989; 68:83-9.

15. Desparmet JF, Yemen TA. Paediatric Anaesthesia Handbook. McGraw Hill. 2002:380-81. 
16. Bernard JD. Regional Anesthesia in Children. In: Miller RD. Anesthesia. $5^{\text {th }}$ Edition. USA, Churchill Livingstone, 2000: p.1560.

17. Herbert K, Claus GK, Christian G, Peter M, et al. Dose - response of caudal ropivacaine in children. Anesthesiology. 1999;90:1339-44.

18. Bano F, Haider S, Sultan ST. Comparison of caudal bupivacaine and bupivacaine-midazolam for peri and postoperative analgesia in children. $\mathrm{J}$ Coll Physicians Surg Pak. 2004;14(2): 65-68.

19. Mahajan R, Batra YK, Grover VK, Kajal J. A comparative study of caudal bupivacaine and midazolam-bupivacaine mixture for postoperative analgesia in children undergoing genitourinary surgery. Int J Clin Pharmacol Ther. 2001; 39(3):11620.
20. Jamali S, Monin S, Begon C, Dubousset A, Ecoffey $C$. Clonidine in pediatric caudal anaesthesia. Anesth Analg. 1994; 78:663-6.

21. Qureshi SM, Taifoor ul Islam S. Usefulness of caudal block in children. Ann King Edward Med Coll. 1999; 5(1): 38-40.

22. Khan RA, Hussain RM. A comparative study of caudal epidural block, single dose bupivacaine versus tramadol for postoperative analgesia in children. Pak Armed Forces Med J. 2002; 52(2): 150-3.

23. Goddard JM, Pickup SE. Postoperative pain in children. Anaesthesia. 1996; 51:588-91.

24. Wong DL, Baker CM. Pain in children. Pediatr Nurs. 1998; 14: 9-17.

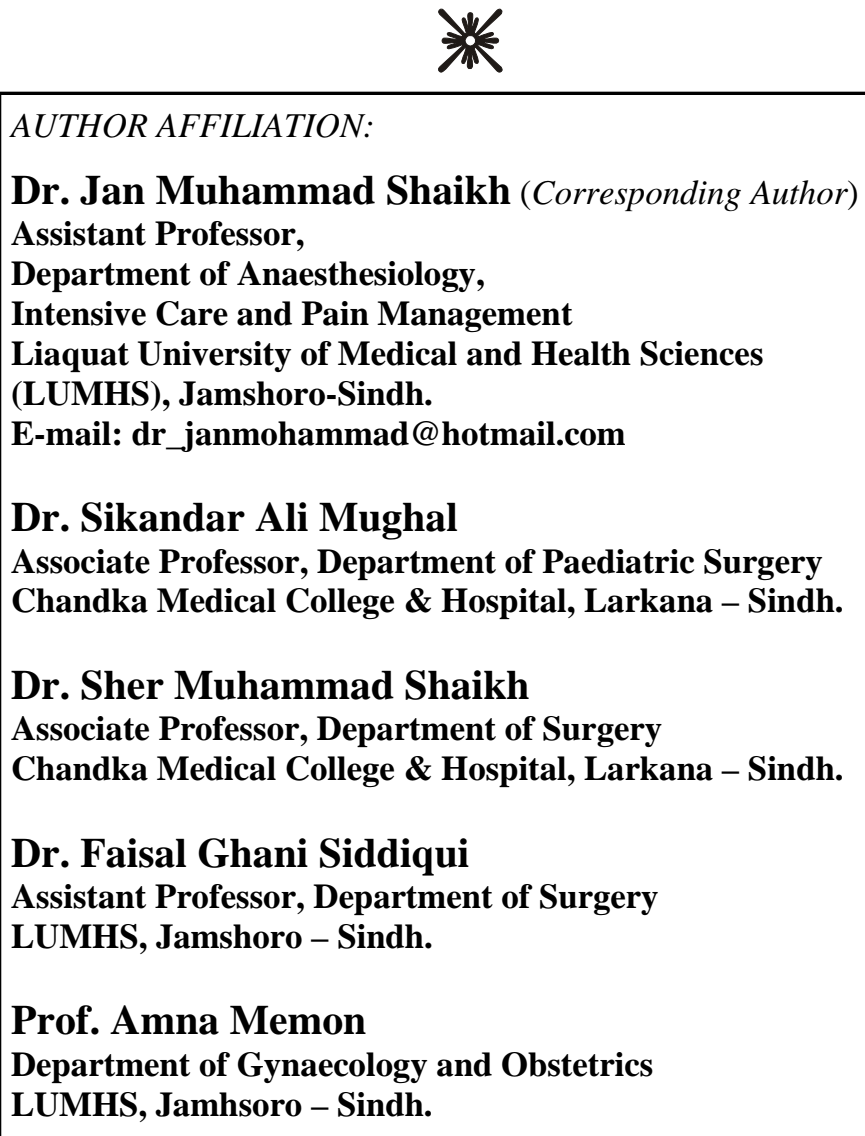

